RUTMech, t. XXXIV, z. 89 (3/17), lipiec-wrzesień 2017, s. 325-332

\author{
Piotr CICHOSZ ${ }^{1}$ \\ Marek KOLODZIEJ ${ }^{2}$ \\ Paweł KAROLCZAK ${ }^{3}$ \\ Maciej KOWALSKI ${ }^{4}$ \\ Hubert SKOWRONEK ${ }^{5}$ \\ Kamil WASZCZUK ${ }^{6}$
}

\title{
FAZOWNIK SAMOCZYNNY Z KASETKĄ NAPINANĄ ELEMENTEM SPRĘŻYSTYM
}

\begin{abstract}
Jednym z problemów, które generują znaczne koszty oraz zwiększają czasochłonność procesów technologicznych, są czynności związane z fazowaniem krawędzi obrobionych wcześniej przedmiotów. Problem ten jest szczególnie istotny w przypadku obróbki seryjnej i masowej. Dostępne na rynku rozwiązania konstrukcyjne narzędzi do fazowania z ostrzami sprężystymi nie dają możliwości regulowania wielkości wykonywanych fazek. W pracy zamieszczono nową konstrukcję fazownika, w którym płytka skrawająca jest zamocowana w kasetce napinanej sprężyną. W celu możliwości regulowania wielkości fazki w kasetce została zaprojektowana płoza ślizgowa. Omówiono również zalety i wady prezentowanej konstrukcji wraz z możliwościami dalszych usprawnień.
\end{abstract}

Słowa kluczowe: narzędzie skrawające, fazowanie, kasetka

\section{Wprowadzenie}

Wraz z rozwojem zautomatyzowania procesów produkcji i stawianiem coraz wyższych wymagań produkowanym elementom maszyn konieczne jest poszukiwanie skutecznych, ekonomicznych metod obróbki, której zadaniem będzie zapewnienie wysokiej jakości wykonywanych elementów. Końcowa obróbka krawędzi w wielu przypadkach ma kluczowe znaczenie dla późniejszych użytkowych i estetycznych walorów wytwarzanych elementów. Konieczność stosowania tych dodatkowych zabiegów, takich jak fazowanie i gratowanie, wynika z przesłanek konstrukcyjnych bądź niedoskonałości stosowanych narzędzi i procesów, w wyniku których powstają niedopuszczalne wady w postaci zadziorów.

\footnotetext{
${ }^{2}$ Autor do korespondencji/corresponding author: Marek Kołodziej, Politechnika Wrocławska, ul. Łukasiewicza 5, 50-371 Wrocław, tel.: 7132041 81, e-mail: marek.kolodziej@pwr.edu.pl

1,3,4,5,6 Piotr Cichosz, Paweł Karolczak, Maciej Kowalski, Hubert Skowronek, Kamil Waszczuk; Politechnika Wrocławska, e-mail: piotr.cichosz@pwr.edu.pl; pawel.karolczak@pwr.edu.pl; maciej.kowalski@pwr.edu.pl; hubert.skowronek@pwr.edu.pl; kamil.waszczuk@pwr.edu.pl
} 
Ich usuwanie jest często kłopotliwe i generuje koszty. Opis i próba zdefiniowania występujących na niewykończonych krawędziach zadziorów przysparza wielu trudności. W zależności od tego, na jakim aspekcie ich występowania skupiają się autorzy poświęconych temu zjawisku publikacji [m.in. 5], spotyka się bardzo różne definicje. Spośród stosowanych w przemyśle maszynowym rodzajów obróbki krawędzi należy wyróżnić cztery podstawowe (rys. 1). Są to: gratowanie (usuwanie zadziorów), tępienie, fazowanie oraz zaokrąglanie [2, 3].

a)

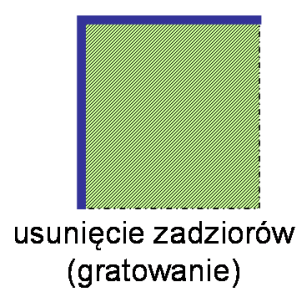

b)

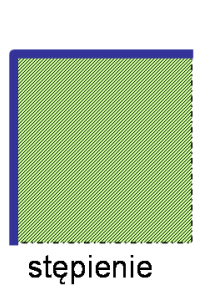

c)

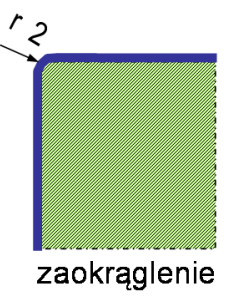

d)

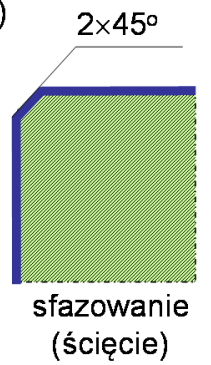

Rys. 1. Rodzaje obróbek krawędzi

Fig. 1. Types of edge machining

Fazowaniem zwykło się określać proces mający na celu usunięcie z ostrej krawędzi pewnej części materiału, celem wytworzenia stępienia o ściśle określonej geometrii. Ze względu na sprecyzowane w dokumentacji technicznej cechy geometryczne wykonuje się je głównie drogą obróbki mechanicznej, czyli przy zastosowaniu różnego rodzaju frezów, ściernic, noży tokarskich i wytaczadeł. Zazwyczaj podczas przeprowadzania tego rodzaju obróbki stosuje się wysokie parametry skrawania, co jest możliwe dzięki niewielkiemu stosunkowi szerokości i głębokości skrawania do średnicy narzędzia. Ponadto coraz większe zastosowanie znajdują narzędzia wielozadaniowe, zespołowe bądź modułowe, które dają możliwość szybszego i dokładniejszego kształtowania fazek, często równocześnie $\mathrm{z}$ innym rodzajem obróbki.

Narzędzie przedstawione na rys. 2 jest konstrukcją prototypową, w której zastosowano mechanizm umożliwiający dokładną regulację wymiaru wykonywanej fazki. Jego działanie opiera się na opatentowanej kasetce do samoczynnego wykonywania fazek. Istota działania kasetki polega na tym, że jest ona wyposażona w rolkę oporową 8, usytuowaną stycznie do stożkowych powierzchni 7 i 12 oraz krawędzi skrawających 6 i 9. Rolka 8 dotyka obrabianej fazki swoją powierzchnią oporową 10 lub $11 \mathrm{w}$ miejscu, gdzie ma być zakończona fazka. Ostrza 1, zamocowane suwliwie w korpusie kasetki 5, są połączone z uchwytem 13 rolki prowadzącej. Ostrza wraz z rolką oporową są dociskane sprężyście za pomocą wkrętu 2 i sprężyny 3 do powierzchni oporowych 4 gniazda kasetki 5 [1]. W części wykonanych egzemplarzy prototypowych zastosowano ślizgacze $\mathrm{w}$ postaci oddzielnych elementów. 
a)

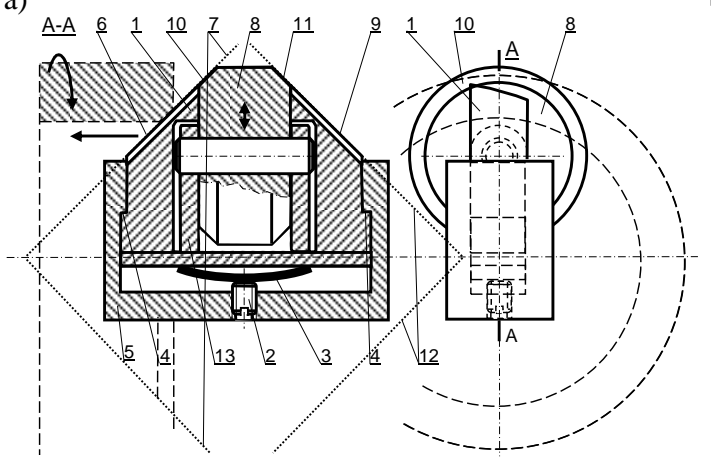

b)

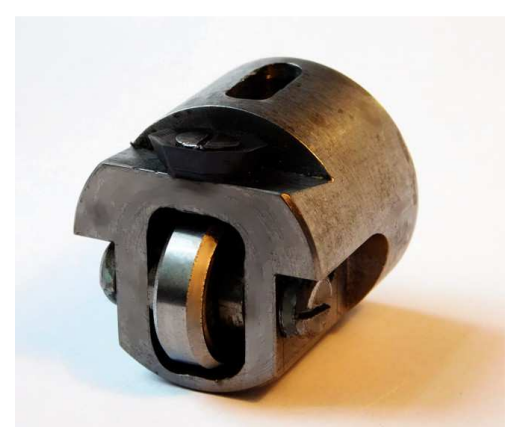

Rys. 2. Kasetka do samoczynnego wykonywania fazek: a) schemat, b) prototyp

Fig. 2. A cassette for self-acting chamfering tool: a) scheme, b) prototype

\section{Konstrukcja narzędzia}

Pierwsze założenia konstrukcji fazownika opierały się na koncepcji wykorzystania ostrza w formie wieloostrzowej płytki handlowej. Rozwiązanie to ma wiele zalet, m.in.: unifikację, dostępność, niższe koszty wytworzenia narzędzia. $\mathrm{Z}$ drugiej strony płytka skrawająca ma przekrój kwadratowy bądź trapezowy, co $\mathrm{z}$ kolei utrudnia wykonanie gniazda w korpusie narzędzia. Jest to spowodowane tym, że w takim rozwiązaniu fazownika ostrze musi się przesuwać w gnieździe, które zostało wykonane $\mathrm{z}$ dość dokładnym pasowaniem. W przypadku wersji fazownika z kasetką wykonanie gniazda pod mocowanie płytki nie stanowi problemu, gdyż ostrze jest przymocowane „na stałe”, a w czasie pracy przesuwa się kasetka.

Podczas realizacji badań analitycznych konstrukcji fazowników w wersji z kasetką prowadzącą i odrębną rolką prowadzącą pojawiła się koncepcja, aby zamiast rolki prowadzącej użyć kulki (rys. 3). Rozwiązanie to miałoby tę zaletę, że kulki prowadzące wraz z oprawami, w bardzo dużym zakresie wymiarów, są dostępne na rynku w przystępnych cenach. Jednak po zamówieniu kulkowych elementów prowadzących okazało się, że ich oprawy są tak skonstruowane, że nie mogą spełniać roli, do której były przeznaczone. Kołnierze tych opraw okazały się zbyt szerokie, co przeszkadzało w umieszczeniu ich blisko ostrza, a taki jest warunek niezbędny do poprawnego działania kasetki fazującej. Przerobienie opraw również nie było możliwe, wykonano je bowiem z blachy połączonej metodą zagniatania. Każda próba zmniejszenia szerokości kołnierza kończyła się zniszczeniem elementu i wysypaniem mikrokulek, które służyły jako ruchome łożysko podporowe zasadniczej, większej kulki prowadzącej. $Z$ tego powodu w dalszej części badań zrezygnowano z takiego rozwiązania konstrukcyjnego. 


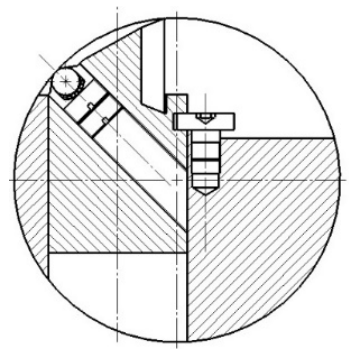

Rys. 3. Konstrukcja fazownika z kasetką oraz kulką prowadzącą

Fig. 3. Construction of the chamfering tool with cassette and guiding ball

Po wykonaniu analiz konstrukcyjnych okazało się, że płoza ślizgowa w formie rolki prowadzącej bądź kulki powoduje znaczne zwiększenie wymiarów fazownika. Wymiar fazownika ma istotne znaczenie, gdyż decyduje o średnicach kształtowanych otworów. Większość otworów, w których są wykonywane fazki, to otwory o stosunkowo małych średnicach, tworzone najczęściej za pomocą wierteł. Problemem jest wykonanie fazki lub choćby tylko usunięcie zadziorów $\mathrm{z}$ otworu u jego wylotu. Trudności te pogłębiają się wraz ze zmniejszaniem się średnicy wykonywanego otworu. Dość ważnym kryterium w ocenie poprawności konstrukcji fazownika jest zatem możliwość jego miniaturyzacji i to w takim stopniu, aby dało się umieszczać go w korpusach wierteł, tworząc z nich narzędzia wielozadaniowe. Takie narzędzie pozwala zwiększyć wydajność obróbki, uprościć technologię wykonania otworów oraz zmniejszyć liczbę narzędzi koniecznych do jego wykonania.

Biorąc to pod uwagę, zaproponowano rozwiązanie fazowników, w którym zamiast elementu obrotowego w postaci rolki lub kulki prowadzącej zastosowano elementy ślizgowe w postaci:

a) walcowej ze ściętym stożkiem (rys. 4a, b). Koniecznej regulacji wysunięcia płozy celem ustawienia wymiaru fazki dokonuje się przez obrót śruby,

b) prostopadłościanu z zaokrąglonymi krawędziami zintegrowanego ze śrubą ustalającą. Regulacja wysunięcia płozy ślizgowej odbywa się za pomocą śruby (rys. 4c),

c) zaokrąglonej bryły przestrzennej zintegrowanej z kasetką. W rozwiązaniu tym płoza ślizgowa jest przytwierdzona do kasetki (gniazda), która na obwodzie ma gwint drobnozwojny. Przekręcanie gniazda umożliwia skokowe, z uwagi na obrót kasetki jedynie o kąt $n \times \pi / 2$, wysunięcie płozy ślizgowej (rys. 4d). 


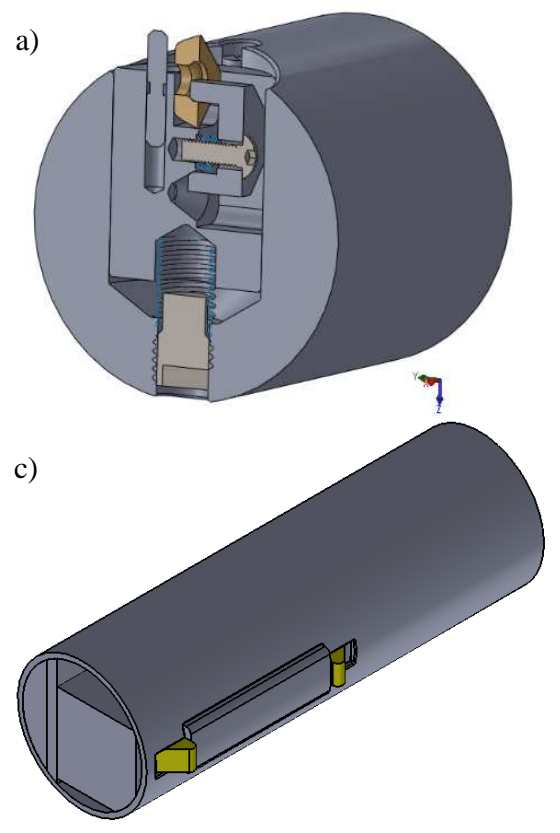

b)

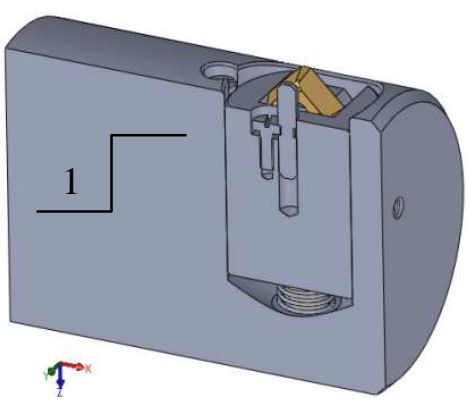

d)

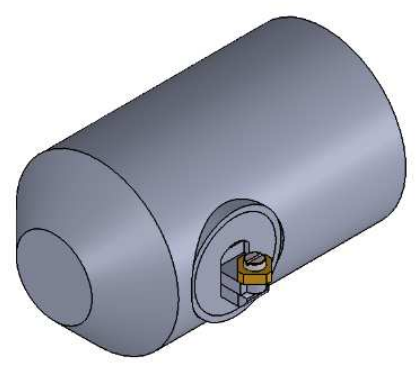

Rys. 4. Fazowniki z kasetką oraz różnymi konstrukcjami płozy ślizgowej w postaci: a) i b) obrotowego kołka w kształcie walca ze ściętym stożkiem - widok od strony czołowej z przekrojem poprzecznym i w przekroju bocznym, c) prostopadłościanu z zaokrąglonymi krawędziami, d) połączonej z kasetką na stałe

Fig. 4. Chamfering tool with cassette and various sliding skid constructions in the form of: a) and b) rotary crankshaft with the truncated cone - frontal view with cross section and lateral cross section, c) cuboid with rounded edges, d) connected permanently to the cassette

\section{Badania doświadczalne skrawania}

Badania poprawności wykonywanych fazek przeprowadzono dla rozwiązania z płozą walcową ze ściętym stożkiem (rys. 5). Badania zrealizowano na tokarce uniwersalnej TUR50S. W celu weryfikacji efektów pracy fazownika badania przeprowadzono dla żeliwa EN GJL 250 przy parametrach skrawania, które są stosowane w obróbce wykończeniowej, tj. $f=0,08 \mathrm{~mm} / \mathrm{obr}$., prędkość skrawania $v_{c}=45 \mathrm{~m} / \mathrm{min}$. Zmiennymi była głębokość skrawania oraz metoda obróbki na sucho i ze smarowaniem. Otrzymane wyniki (w postaci fazek) rejestrowano za pomocą urządzenia DinoLite. Dla wszystkich prób zmierzono także składowe siły skrawania (głównie siłę odporową $F_{p}$ ) przy użyciu siłomierza tokarskiego firmy Kistler (rys. 6).

Niestety, zaproponowana konstrukcja narzędzia do fazowania nie pozwoliła na poprawne osiągnięcie zamierzonego wyniku w postaci możliwości uzyskiwania regulowanej wielkości fazek (rys. 7). W toku prowadzonych badań stwier- 
dzono, że wysuwanie obrotowej płozy powoduje co prawda zwiększanie wielkości otrzymywanej fazki, jednak kształt fazki odbiega od założonego, a kąt fazki zmienia się od około 30 do $60^{\circ}$, w zależności od położenia ostrza względem regulowanej płozy obrotowej. Powodem takiego stanu rzeczy może być bardzo trudna do określenia wzajemna współpraca dwóch powierzchni stożkowych kształtowanej fazki i płozy obrotowej, które mają względem siebie zwichrowane osie.

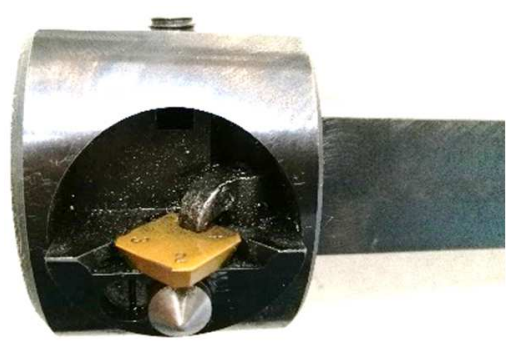

Rys. 5. Narzędzie do wykonywania fazek z płozą walcową ze ściętym stożkiem

Fig. 5. A tool for chamfering with cylindrical skid
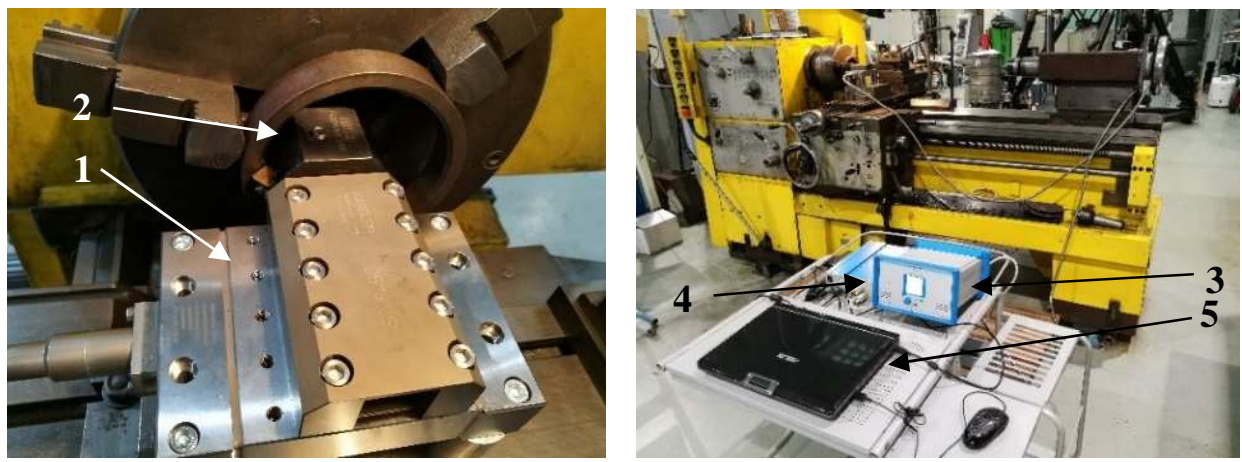

Rys. 6. Widok toru do pomiaru składowych siły skrawania z zamontowanym fazownikiem; 1 - siłomierz, 2 - narzędzie do fazowania, 3 - wzmacniacz ładunku, 4 - system akwizycji danych, 5 - komputer przenośny z programem DynoWare rejestrujacym mierzone siły

Fig. 6. View of the track for measuring the cutting force components with the mounted chamfering tool; 1 - dynamometer, 2 - chamfering tool, 3 - charge amplifier, 4 - acquisition data system, 5 - notebook with DynoWare software for registration of measured forces

Wspomniana konstrukcja fazownika wpłynęła na dużą niestabilność procesu fazowania, związaną m.in. z elastycznie podpartym ostrzem na sprężynie, co można stwierdzić, obserwując siły oddziaływania między narzędziem a przedmiotom obrabianym. Na rysunku 8 zamieszczono przykładowy przebieg zmierzonej składowej siły odporowej $F_{p}$ dla żeliwa podczas skrawania z zastosowaniem chłodzenia. Przebieg ten jest sumą przebiegów siły skrawania i siły oddziaływania obrotowej płozy z powierzchnią wykonanej fazki. 


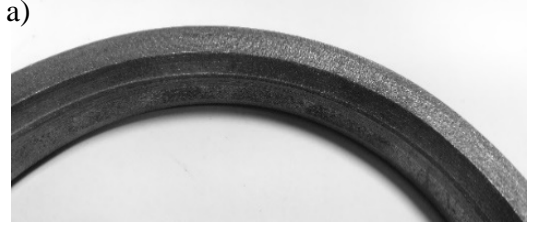

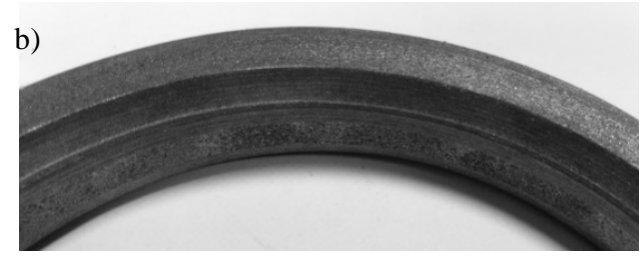

b)

Rys. 7. Widok fazki na pierścieniu żeliwnym wykonanej: a) bez chłodzenia, b) z chłodzeniem

Fig. 7. View of the chamfer made on the cast iron ring: a) without cooling, and b) with cooling

Rys. 8. Przebieg składowej siły odporowej $F_{p}$ podczas wykonywania fazki $\mathrm{z}$ chłodzeniem dla żeliwa, $a_{p}=5 \mathrm{~mm} ; f=0,08$ $\mathrm{mm} / \mathrm{obr}$; $v_{c}=45 \mathrm{~m} / \mathrm{min}$

Fig. 8. The variation of the component of the $F_{p}$ force during making the chamfer with cooling on the cast iron, $a_{p}=5 \mathrm{~mm}$; $f=0.08 \mathrm{~mm} / \mathrm{rev} ; v_{c}=45 \mathrm{~m} / \mathrm{min}$

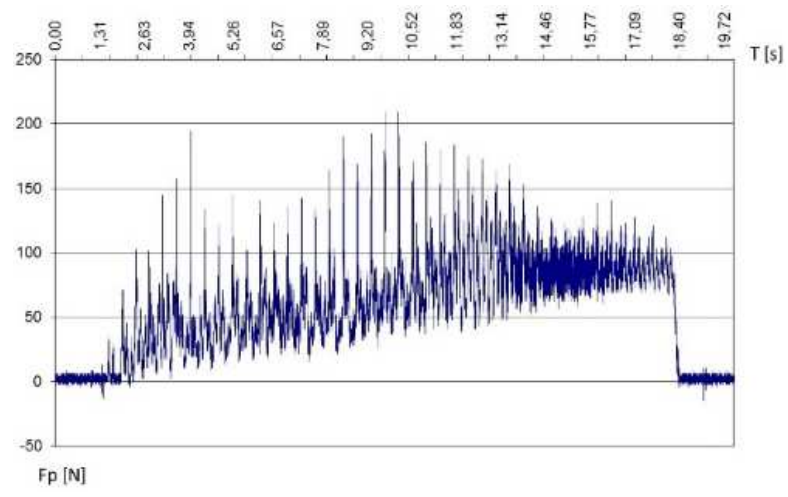

\section{Podsumowanie}

Przedstawiona w artykule konstrukcja narzędzia do samoczynnego fazowania ma przede wszystkim służyć do wykonywania fazek w sposób automatyczny, $\mathrm{z}$ możliwością regulacji wielkości fazki. W tym celu zostały opracowane różne koncepcje konstrukcyjne, które jednak nie zawsze dawały pożądane efekty. $\mathrm{W}$ wyniku prac badawczych zostało zaproponowane rozwiązanie konstrukcyjne $\mathrm{z}$ ostrzem dostępnym handlowo, w którym elementem ślizgowym służącym do regulacji wielkości fazki jest ścięty stożek. W wyniku przeprowadzonej weryfikacji na stanowisku badawczym uzyskano fazki, które z jednej strony można uzyskać w sposób prosty i powtarzalny, z drugiej jednak strony zmieniający się kąt uzyskanych fazek nie do końca odpowiada postawionym początkowym założeniom. Dalsze prace badawcze nad tą wersją narzędzia do fazowania powinny się skupić nad poprawnym określeniem wzajemnej współpracy ślizgacz-ostrze i takim przeprojektowaniem konstrukcji, która pozwoli uzyskać prawidłowy kształt fazki. 


\section{Literatura}

[1] Cichosz P.: Ostrze do samoczynnego wykonywania fazek, Patent PL 213332, Zgłoszono 14.09.2009, udzielono patentu 28.02.2013.

[2] Cichosz P., Kuzinovski M: Metody wykonywania fazek i gratowania krawędzi, Mechanik, 84 (2011) 674-681.

[3] Cichosz P., Karolczak P., Kołodziej M., Kowalski M., Kuzinovski M., Skowronek H., Waszczuk K.: Elementy sprężyste fazowników samoczynnych, Mechanik, 89 (2016) 1424-1427.

[4] Drabik L., Sobol E.: Słownik języka polskiego, PWN, Warszawa 2007.

[5] Matuszak J.: Powstawanie i usuwanie zadziorów w obróbce skrawaniem, Politechnika Lubelska, Lublin 2004.

\section{THE SELF-ACTING CHAMFERING TOOL WITH CASSETTE TENSIONED BY SPRING ELEMENT}

\section{S u m m a r y}

The chamfering of the edges of previously machined parts is one of the problems that generates significant costs and increases the time consuming process. This problem is particularly important in lot and mass processing. The chamfering tools with resilient blades available on the market do not offer the ability to adjust the size of the chamfer. In this paper a new chamfering tool design, in which the cutting insert is fixed in a spring-loaded cassette is presented. In order to adjust the size of the chamfer, a sliding skid has been designed in the cassette. The advantages and disadvantages of the presented construction along with the possibilities of further improvements are also discussed.

Keywords: cutting tool, chamfering, cassette

DOI: $10.7862 / \mathrm{rm} .2017 .28$

Otrzymano/received:12.07.2017

Zaakceptowano/accepted: 18.09 .2017

Projekt finansowany przez Narodowe Centrum Badań i Rozwoju w ramach programu: INNOTECH III 